\title{
A novel PITX2c loss-of-function mutation underlies lone atrial fibrillation
}

\author{
YI-MENG ZHOU ${ }^{1,2}$, PENG-XIANG ZHENG ${ }^{3}$, YI-QING YANG ${ }^{4}$, \\ ZHI-MING GE $^{1}$ and WEI-QIANG KANG ${ }^{1,5}$
}

\begin{abstract}
${ }^{1}$ The Key Laboratory of Cardiovascular Remodeling and Function Research, Chinese Ministry of Education and Chinese Ministry of Health, Shandong University Qilu Hospital, Jinan, Shandong 250012;

Departments of ${ }^{2}$ Emergency Medicine and ${ }^{3}$ Cardiology, Yangpu District Central Hospital, Shanghai 200090;

${ }^{4}$ Department of Cardiology and Cardiovascular Research, Shanghai Chest Hospital, Shanghai Jiao Tong University, Shanghai 200030; ${ }^{5}$ Department of Cardiology, Qingdao Municipal Hospital, Qingdao, Shandong 266011, P.R. China
\end{abstract}

Received May 26, 2013; Accepted July 29, 2013

DOI: $10.3892 /$ ijmm.2013.1463

\begin{abstract}
Atrial fibrillation (AF) is the most common form of sustained cardiac arrhythmia responsible for substantial morbidity and significantly increased mortality rates. A growing body of evidence documents the important role of genetic defects in the pathogenesis of AF. However, AF is a heterogeneous disease and the genetic determinants for AF in an overwhelming majority of patients remain unknown. In the present study, a cohort of 100 unrelated patients with lone AF and a total of 200 unrelated, ethnically matched healthy individuals used as controls, were recruited. The whole coding exons and splice junctions of the pituitary homeobox 2c (PITX2c) gene, which encodes a paired-like homeobox transcription factor required for normal cardiovascular morphogenesis, were sequenced in the 100 patients and 200 control subjects. The causative potential of the identified mutation of PITX2c was predicted by MutationTaster and PolyPhen-2. The functional characteristics of the PITX2c mutation were assayed using a dual-luciferase reporter assay system. Based on the results, a novel heterozygous PITX2c mutation (p.T97A) was identified in a patient with AF. The missense mutation was absent in the
\end{abstract}

Correspondence to: Professor Wei-Qiang Kang, The Key Laboratory of Cardiovascular Remodeling and Function Research, Chinese Ministry of Education and Chinese Ministry of Health, Shandong University Qilu Hospital, 44 Wenhuaxi Road, Jinan, Shandong 250012, P.R. China

E-mail:kwq1021@163.com

Professor Yi-Qing Yang, Department of Cardiology and Cardiovascular Research, Shanghai Chest Hospital, Shanghai Jiao Tong University, 241 West Huaihai Road, Shanghai 200030, P.R. China

E-mail: yang99yang66@hotmail.com

Key words: atrial fibrillation, genetics, transcriptional factor, pituitary homeobox $2 \mathrm{c}$, reporter gene
400 reference chromosomes and was automatically predicted to be disease-causing. Multiple alignments of PITX2c protein sequences across species revealed that the altered amino acid was completely conserved evolutionarily. Functional analysis demonstrated that the mutant PITX2c protein was associated with significantly decreased transcriptional activity when compared with its wild-type counterpart. The findings of the present study firstly link the PITX2c loss-of-function mutation to lone AF, and provide novel insight into the molecular mechanisms underlying AF, suggesting the potential implications for the early prophylaxis and allele-specific therapy of this common type of arrhythmia.

\section{Introduction}

Atrial fibrillation (AF), a supraventricular tachyarrhythmia characteristic of the rapid and chaotic electrical activity of the atria with consequent deterioration of atrial mechanical function, is the most prevalent type of sustained cardiac arrhythmia in humans, afflicting roughly one-third of all hospitalized patients with miscellaneous heart rhythm disturbances (1). The prevalence of AF is approximately $1 \%$ in the general population and increases drastically with advancing age, increasing from $<1 \%$ in individuals aged $<60$ years up to $\sim 10 \%$ in those $>80$ years of age (1). According to the report from the Framingham Heart Study, the lifetime risk of developing AF is approximately one in four among subjects older than 40 years (2). In the United States, the number of individuals affected by AF is currently estimated at 2.3 million and is projected to exceed 10 million by 2050 (3). This common cardiac dysrhythmia may lead to poor quality of life, decreased exercise tolerance, cognitive impairment, tachycardiomyopathy, thromboembolism, congestive heart failure and even death (1). The mortality rate of patients with AF is approximately twice that of age- and gender matched patients with normal heart rhythm, which persists even after the adjustment for pre-existing cardiovascular conditions (4). Patients with AF are at a 2- to 7-fold increased risk of ischemic stroke compared with those without AF and 15 to $20 \%$ of all strokes 
are attributed to AF (5). Notably, the risk of thromboembolic stroke ascribed to AF also increases steeply with increasing age, ranging from $1.5 \%$ for persons aged 50 to 59 years to $23.5 \%$ for persons aged 80 to 89 years (5). Hence, AF has imposed a heavy economic burden on patients and health care systems and the socioeconomic burden is anticipated to increase drastically in the future with life expectancies increasing (6). Despite the high prevalence and important clinical significance, the molecular mechanisms underlying AF remain poorly understood.

Traditionally, AF has been referred to as a complication of diverse cardiac and systemic disorders, including coronary heart disease, rheumatic heart disease, congenital heart disease, pulmonary heart disease, cardiomyopathy, cardiothoracic surgery, myocarditis, congestive heart failure, essential hypertension, diabetes mellitus and hyperthyroidism (1). However, in 12 to $30 \%$ of all AF patients and 20 to $45 \%$ of younger AF patients, AF occurs separately in the absence of underlying diseases or precipitating factors, a condition termed as lone or idiopathic AF, of which at least $15 \%$ of cases have a positive family history, thus defined as familial $\operatorname{AF}(1,7)$. A growing body of epidemiological research has demonstrated the familial aggregation of AF and the increased vulnerability to $\mathrm{AF}$ in the close relatives of patients with $\mathrm{AF}$, strongly suggesting that genetic risk factors play a pivotal role in the pathogenesis of AF in a subset of patients (8-14). In previous studies, using genome-wide scanning with polymorphic microsatellite markers and linkage analysis, AF susceptibility loci were mapped on human chromosomes 10q22, 6q14-16, 11p15.5, 5p15, 10p11-q21 and 5p13, where AF-causative mutations in two genes, potassium voltage-gated channel, KQT-like subfamily, member 1 (KCNQ1) on chromosome 11p15.5 and nucleoporin $155 \mathrm{kDa}$ (NUP155) on chromosome 5p13, were identified and functionally characterized (15-21). Direct analyses of candidate genes unveiled a high number of AF-related genes, including potassium voltage-gated channel, Isk-related family, member 2 (KCNE2), potassium voltage-gated channel, subfamily $\mathrm{H}$ (eag-related), member 2 (KCNH2), potassium inwardly-rectifying channel, subfamily J, member 2 (KCNJ2), potassium voltage-gated channel, shaker-related subfamily, member 5 (KCNA5), sodium channel, voltage-gated, type V, alpha subunit (SCN5A), sodium channel, voltage-gated, type IV, beta subunit (SCN4B), atrial natriuretic peptide (ANP), gap junction protein, alpha 5, $40 \mathrm{kDa}$ (GJA5), GATA binding protein (GATA)4, GATA5, GATA6 and NK2 homeobox 5 (NKX2-5) (22-42). Nevertheless, AF is a genetically heterogeneous disease and the genetic basis underlying AF in an overwhelming majority of patients remains to be elucidated.

In a previous study, Gudbjartsson et al (43) performed a genome-wide association scan, followed by replication studies in three populations of European descent and a Chinese population and found a strong association between two sequence variants (rs2200733 and rs10033464) on chromosome 4q25 and AF. They demonstrated that $\sim 35 \%$ of individuals of European descent had at least one of the variants and that the risk of AF increased by 1.72 and 1.39 per copy. The association with the stronger variant is replicated in the Chinese population, where it was carried by $75 \%$ of individuals, and the risk of AF was increased by 1.42 per copy. Subsequently, Kääb et al (44) also confirmed the strong association of the non-coding polymorphisms, rs2200733 and rs10033464, with AF in four independent cohorts of European descent. In two independently collected cardiac surgery cohorts, the two variants within the chromosome $4 \mathrm{q} 25$ region were independently associated with post-operative AF following coronary artery bypass graft surgery after adjusting for clinical covariates (45). Furthermore, the two sequence variants have been reported to increase the risk of the early and late recurrence of AF following catheter ablation (46) and have been shown to be genetic modifiers of rare ion channel mutations linked to familial AF (47). The gene closest to these sequence variants is pituitary homeobox 2 (PITX2), a member of the PITX family of transcription factors that play an essential role in embryonic morphogenesis, with PITX2c being the predominant isoform expressed in the embryonic and adult heart (48). Emerging evidence highlights the pivotal role of PITX2c in the embryonic development of the left atrium, the cardiac conduction system and pulmonary venous myocardium, a major source of ectopic activity involved in the initiation and maintenance of AF (49,50); the abnormal expression of PITX2c has also been implicated in the increased susceptibility to AF (51-53). These findings warrant the screening of PITX2c as a preferred candidate gene for lone AF.

\section{Materials and methods}

Study subjects. A cohort of 100 unrelated patients with lone AF was enlisted from the Han Chinese population. A total of 200 ethnically matched, unrelated healthy individuals were enrolled as the controls. Peripheral venous blood samples were prepared and clinical data, including medical records, electrocardiogram and echocardiography reports were collected. The study subjects were clinically classified using a consistently applied set of definitions $(7,34)$. Briefly, AF was diagnosed by a standard 12-lead electrocardiogram demonstrating no $P$ waves and irregular R-R intervals irrespective of clinical symptoms. Lone AF was defined as AF occurring in individuals $<60$ years of age without other cardiac or systemic diseases by physical examination, electrocardiogram, transthoracic echocardiogram and extensive laboratory tests. Subjects were classified as 'healthy' if they were asymptomatic and had a normal electrocardiogram with no history of AF. Paroxysmal AF was defined as AF lasting $>30 \mathrm{sec}$ that terminated spontaneously. Persistent $\mathrm{AF}$ was defined as $\mathrm{AF}$ lasting $>7$ days and requiring either pharmacological therapy or electrical cardioversion for termination. AF that was refractory to cardioversion or that was allowed to continue was classified as permanent. The present study was performed in compliance with the ethical principles of the revised Declaration of Helsinki (48th WMA General Assembly, Somerset West, Republic of South Africa, 1996). The study protocol was reviewed and approved by the local institutional ethics committee and written informed consent was obtained from all participants prior to enrollment in this study.

Genotyping for PITX2c. Genomic DNA was extracted from the peripheral venous blood lymphocytes of all the participants using the Wizard Genomic DNA Purification kit (Promega, Madison, WI, USA). The coding exons and intron-exon boundaries of PITX2c were sequenced in the 100 unrelated patients 
Table I. Intronic primers used to amplify the coding exons and exon-intron boundaries of PITX2c.

\begin{tabular}{lllc}
\hline Exon & \multicolumn{1}{c}{ Forward primer (5' to 3') } & Reverse primer (5' to 3') & Amplicon size (bp) \\
\hline 1 & CAG CTT GGC TTG AGA ACT CG & TGA CTT CCT TGG GGC GAG AG & 442 \\
2 & CAG CTC TTC CAC GGC TTC TG & GCT GCC TTC CAC ATT CTC TC & 387 \\
3 & AAT CTG CAC TGT GGC ATC TG & AGT CTT TCA AGG GCG GAG TT & 677 \\
\hline
\end{tabular}

PITX2c, pituitary homeobox 2c.

with lone AF. The 200 control individuals were subsequently genotyped for PITX2c due to the identified mutation in patients with AF. The referential genomic DNA sequence of PITX2c was derived from GenBank [accession no. NC_000004; available at the National Center for Biotechnical Information (NCBI; http://www.ncbi.nlm.nih.gov/)]. With the aid of the on-line Primer 3 program (http://frodo.wi.mit.edu), the primers used to amplify the entire coding region and splice junctions of PITX $2 c$ by polymerase chain reaction (PCR) were designed as presented in Table I. PCR was carried out using HotStar Taq DNA Polymerase (Qiagen, Hilden, Germany) on a Veriti Thermal Cycler (Applied Biosystems, Foster City, CA, USA), with standard conditions and concentrations of reagents. Amplified products were analyzed on $1 \%$ agarose gels stained with ethidium bromide and purified using the QIAquick Gel Extraction kit (Qiagen). Both strands of each amplicon were sequenced with a BigDye ${ }^{\circledR}$ Terminator v3.1 Cycle Sequencing kit under an ABI PRISM 3130xl DNA Analyzer (both from Applied Biosystems). The sequencing primers were the same as those previously designed for specific region amplification. The DNA sequences were viewed using DNA Sequencing Analysis software v5.1 (Applied Biosystems). The variant was validated by re-sequencing an independent PCR-generated amplicon from the subject and met the quality control thresholds with a call rate $>99 \%$. Additionally, for an identified sequence variant, the Exome Variant Server (EVS; http://evs. gs.washington.edu/EVS) and the NCBI single nucleotide polymorphism (SNP; http://www.ncbi.nlm.nih.gov/SNP) online databases were queried to confirm its novelty.

Multiple alignments of PITX2c protein sequences. Multiple PITX2c protein sequences across various species were aligned using an online program MUSCLE, v3.6 (http://www.ncbi. nlm.nih.gov/).

Prediction of the causative potential of a PITX2c sequence variation. The disease-causing potential of a PITX2c sequence variation was predicted by the online program MutationTaster (http://www.mutationtaster.org), which automatically yielded a probability for the variation to be either a pathogenic mutation or a benign polymorphism. Of note, the P-value used in this study is the probability of the correct prediction rather than the probability of error as used in t-test statistics (i.e., a value close to 1 indicates a high accuracy of the prediction). In addition, another online program PolyPhen-2 (http://genetics.bwh. harvard.edu/pph2) was also used to evaluate the pathogenic likeliness of a mutation.
Expression plasmids and site-directed mutagenesis. The recombinant expression plasmid, PITX2c-pcDNA4, which was constructed by Strungaru et al (54), was a gift from Professor Georges Christé, Physiopathologie des Troubles du Rythme Cardiaque, Faculté de Pharmacie de Lyon, Université Lyon 1, Lyon, France. The atrial natriuretic factor (ANF)-luciferase reporter plasmid, which contains the 2600-bp 5'-flanking region of the $A N F$ gene, namely $\operatorname{ANF}(-2600)-L u c$, was kindly provided by Dr Ichiro Shiojima, from the Department of Cardiovascular Science and Medicine, Chiba University Graduate School of Medicine, Chuo-ku, Chiba, Japan. The identified mutation was introduced into the wild-type PITX2c using the QuickChange II XL Site-Directed Mutagenesis kit (Stratagene, La Jolla, CA, USA) with a complementary pair of primers. The mutant was sequenced to confirm the desired mutation and to exclude any other sequence variations.

Luciferase reporter gene assay. Chinese hamster ovary (CHO) cells were grown in Dulbecco's modified Eagle's medium supplemented with $10 \%$ fetal calf serum, $100 \mathrm{U} / \mathrm{ml}$ penicillin and $100 \mu \mathrm{g} / \mathrm{ml}$ streptomycin. The CHO cells were cultured $24 \mathrm{~h}$ prior to transfection. The ANF(-2600)-Luc reporter construct and an internal control reporter plasmid pGL4.75 (hRluc/CMV; Promega) were used in transient transfection assays to explore the transactivational activity of the PITX2c mutant. CHO cells were transfected with $2 \mu \mathrm{g}$ of wild-type PITX2c-pcDNA4 or mutant PITX2c-pcDNA4 or empty vector pcDNA4, $2.0 \mu \mathrm{g}$ of ANF(-2600)-Luc reporter construct and $0.04 \mu \mathrm{g}$ of pGL4.75 control reporter vector using Lipofectamine ${ }^{\circledR} 2000$ Transfection Reagent (Invitrogen, Carlsbad, CA, USA). For the co-transfection experiments, $1 \mu \mathrm{g}$ of wild-type PITX2c-pcDNA4, $1 \mu \mathrm{g}$ of mutant PITX2c-pcDNA4, $2.0 \mu \mathrm{g}$ of ANF(-2600)-Luc and $0.04 \mu \mathrm{g}$ of pGL4.75 were used. Transfected cells were incubated for $24 \mathrm{~h}$, then lysed and assayed for reporter activities. Firefly luciferase and Renilla luciferase activities were measured using the Dual-Glo Luciferase Assay System (Promega). The activity of the $A N F$ promoter was presented as the fold activation of Firefly luciferase relative to Renilla luciferase. At least three independent experiments were performed for wild-type or mutant PITX2c.

Statistical analysis. The continuous data are expressed as the means \pm standard deviation. Continuous variables were tested for normality of distribution and the Student's unpaired t-test was used to compare numeric variables between two groups. The categorical variables were compared between two groups 
Table II. Baseline clinical characteristics of the 100 unrelated patients with lone AF.

\begin{tabular}{lrc}
\hline Parameter & $\begin{array}{c}\text { No. or } \\
\text { mean }\end{array}$ & $\begin{array}{c}\text { \% or } \\
\text { range }\end{array}$ \\
\hline Male & 53 & 53 \\
Age at initial diagnosis of AF (years) & 45.8 & $20-60$ \\
Age at the time of present study (years) & 52.1 & $21-67$ \\
Type of AF at presentation & & \\
Paroxysmal AF & 62 & 62 \\
Persistent AF & 26 & 26 \\
Permanent AF & 12 & 12 \\
Positive family history of AF & 5 & 5 \\
History of cardioversion & 82 & 82 \\
Implanted cardiac pacemaker & 2 & 2 \\
Resting heart rate (beats/min) & 78.6 & $56-164$ \\
Systolic blood pressure (mmHg) & 132.7 & $90-138$ \\
Diastolic blood pressure (mmHg) & 81.2 & $70-86$ \\
Body mass index (kg/m $\left.{ }^{2}\right)$ & 22.4 & $20-24$ \\
Left atrial dimension (mm) & 36 & $30-40$ \\
Left ventricular ejection fraction & 0.6 & $0.5-0.7$ \\
Fasting blood glucose (mmol/l) & 4.6 & $3.5-5.8$ \\
Total cholesterol (mmol/l) & 4.5 & $3.4-6.2$ \\
Triglycerides (mmol/l) & 1.5 & $0.9-1.7$ \\
Medications & & \\
Amiodarone & 78 & 78 \\
Warfarin & 65 & 65 \\
Digoxin & 12 & 12 \\
Calocker & 10 & 10 \\
\hline & 6 & 6 \\
\hline
\end{tabular}

AF, atrial fibrillation.

using Pearson's Chi-squared test or Fisher's exact test, where appropriate. A two-sided P-value $<0.05$ was considered to indicate a statistically significant difference.

\section{Results}

Clinical characteristics of the study population. A cohort of 100 unrelated patients with lone AF was recruited, clinically evaluated and compared with 200 ethnically matched, unrelated healthy individuals. None of the participants had traditional risk factors for AF. There were no significant differences between the patient and control groups as regards baseline characteristics, including gender, body mass index, blood pressure, fasting blood glucose levels, serum lipid levels, left atrial dimension, left ventricular ejection fraction, heart rate at rest, as well as life style (data not shown). The baseline clinical characteristics of the 100 patients with lone $\mathrm{AF}$ are summarized in Table II.

PITX2c mutation. A heterozygous missense mutation in PITX2c was identified in one of the 100 unrelated patients with lone AF. The total population prevalence of PITX2c mutation based on the patient cohort was $1 \%$. Specifically, a substitution of guanine (G) for adenine (A) in the first nucleotide of codon 97 (c.289A $>\mathrm{G}$ ), predicting the transition of threonine (T) into alanine (A) at amino acid position 97 (p.T97A), was identified in a male patient aged 46 years, who was initially diagnosed with AF at the age of 32 . The mutation carrier had no apparent malformations in the eyes, teeth, umbilicus, or heart and had no positive family history of AF. No relatives from the mutation carrier were available for the genotyping of PITX2c. The sequence chromatograms showing the detected heterozygous PITX2c mutation of c. $289 \mathrm{~A}>\mathrm{G}$ in contrast to its control sequence is shown in Fig. 1 . A representative electrocardiogram of the mutation carrier showing AF is displayed in Fig. 2. A schematic diagram of PITX2c showing the structural domains and the location of the identified mutation is exhibited in Fig. 3 [modified from previous studies $(55,56)]$. This missense mutation was neither observed in the control population nor reported in the EVS and NCBI SNP databases.

Alignment of multiple PITX2c protein sequences across species. A cross-species alignment of PITX2c protein sequences revealed that the altered amino acid was completely conserved evolutionarily (Fig. 4).

Disease-causing potential of the PITX2c variation. The PITX2c sequence variation of c.289A $>\mathrm{G}$ was automatically predicted by MutationTaster to be a disease-causing mutation with the P-value of 1.0. No SNP in the altered region was found in the MutationTaster database. This PITX2c sequence variation was also predicted by PolyPhen-2 to be possibly damaging, with a score of 1.000 (sensitivity 0.00 ; specificity 1.00 ).

Transcriptional activity of the PITX2c mutant. The same amounts of wild-type PITX2c $(2 \mu \mathrm{g})$ and T97A-mutant PITX2c $(2 \mu \mathrm{g})$ activated the $A N F$ promoter ( 8- and 2-fold increase, respectively), when compared with the empty plasmid. When the same amount of wild-type PITX2c $(1 \mu \mathrm{g})$ was transfected in combination with T97A-mutant PITX2c $(1 \mu \mathrm{g})$, the induced activation of the $A N F$ promoter was increased by $\sim 4$-fold, in comparison with the empty plasmid (Fig. 5).

\section{Discussion}

In the present study, a novel heterozygous PITX2c mutation, p.T97A, was identified in a patient with lone AF, which was absent in the 400 reference chromosomes and was predicted to be pathogenic by MutationTaster and PolyPhen-2. A cross-species alignment of PITX2c protein sequences indicated that the altered amino acid was completely conserved evolutionarily. Functional analysis demonstrated that the mutant PITX2c protein was associated with a significantly reduced transcriptional activity. Therefore, it is likely that functionally compromised PITX2c predisposes to AF. 

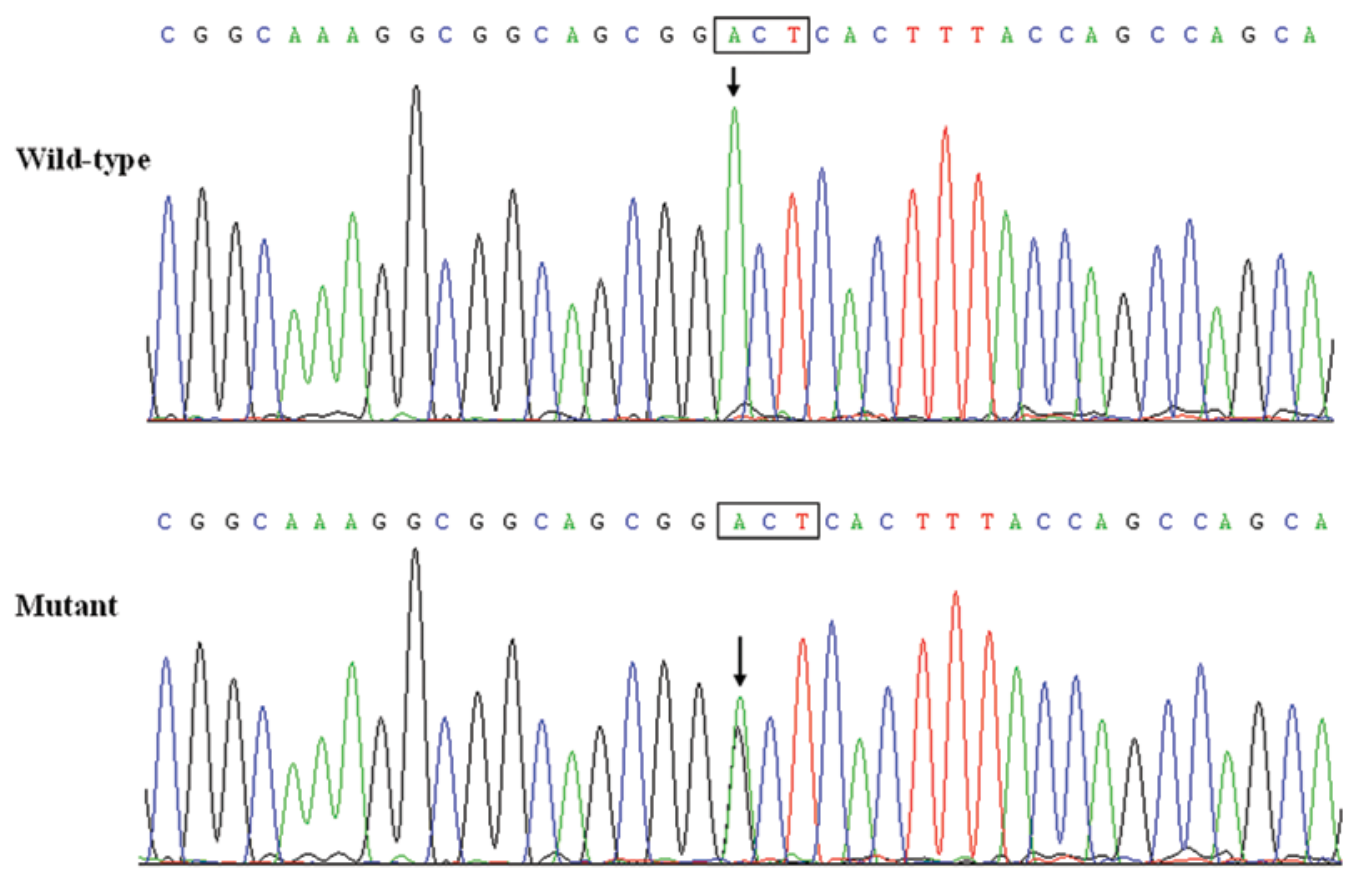

Figure 1. Sequence electropherograms showing the pituitary homeobox 2c (PITX2c) mutation in contrast with its corresponding control. The arrow indicates the heterozygous nucleotides of $\mathrm{A} / \mathrm{G}$ (mutant) or the homozygous nucleotides of $\mathrm{A} / \mathrm{A}$ (wild-type). The rectangle denotes the nucleotides comprising a codon of PITX2c.

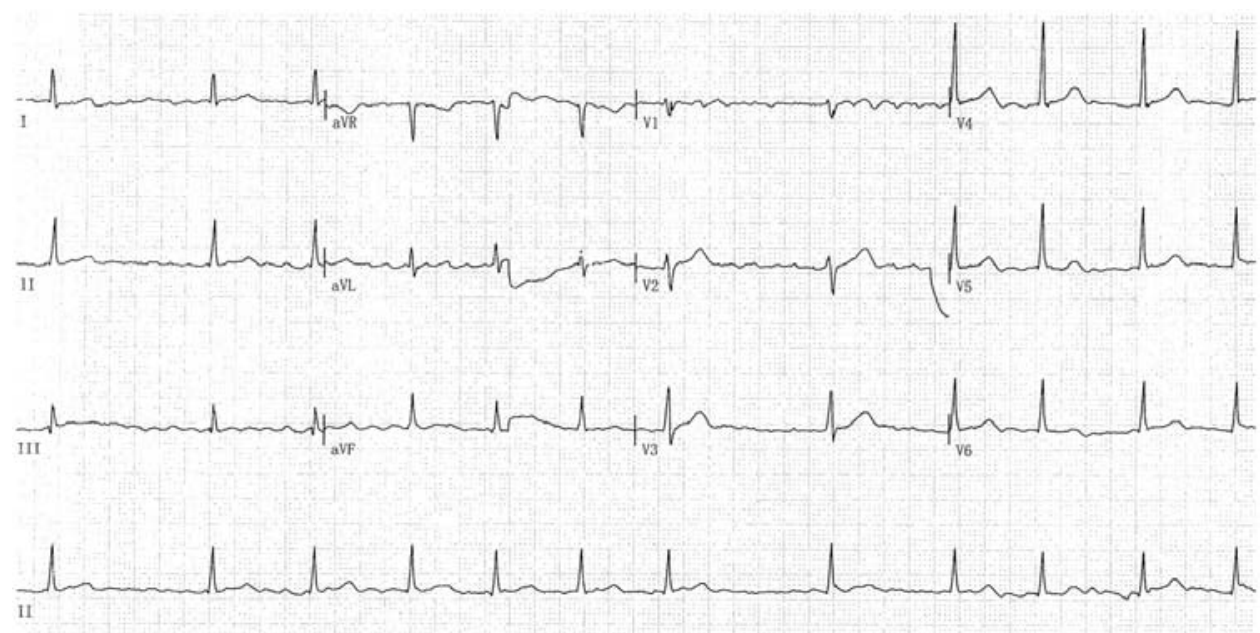

Figure 2. A standard 12-lead electrocardiogram from the mutation carrier with atrial fibrillation.

PITX2c

\begin{tabular}{|c|c|c|c|c|c|c|}
\hline \multicolumn{7}{|c|}{ T97A } \\
\hline NH2- & TAD1 & HD & NLS & TID1 & TAD2 & TID2 \\
\hline
\end{tabular}

Figure 3. Schematic diagram of pituitary homeobox 2c (PITX2c) protein structure with the atrial fibrillation (AF)-related mutation indicated. The mutation identified in a patient with lone AF is shown above the structural domains. NH2, amino-terminus; TAD1, transcriptional activation domain 1 (amino acids 1-90); HD, homeodomain (amino acids 91-151); NLS, nuclear localization signal (amino acids 145-161); TID1, transcriptional inhibitory domain 1 (amino acids 162-212); TAD2, transcriptional activation domain 2 (amino acids 213-285); TID2, transcriptional inhibitory domain 2 (amino acids 286-324); COOH, carboxyl-terminus .

PITX2 is a member of the bicoid-like homeobox transcription factor family. Four different PITX2 transcripts, derived from alternative promoter usage and differential mRNA splicing, have been described. PITX2a, PITX2b and PITX2c differ only in their amino-termini and have been identified in chicks, humans, mice, zebrafish and xenopus, while the fourth isoform, PITX2d, which lacks the amino-terminal domain and most of the homeodomain, has only been observed in humans. 


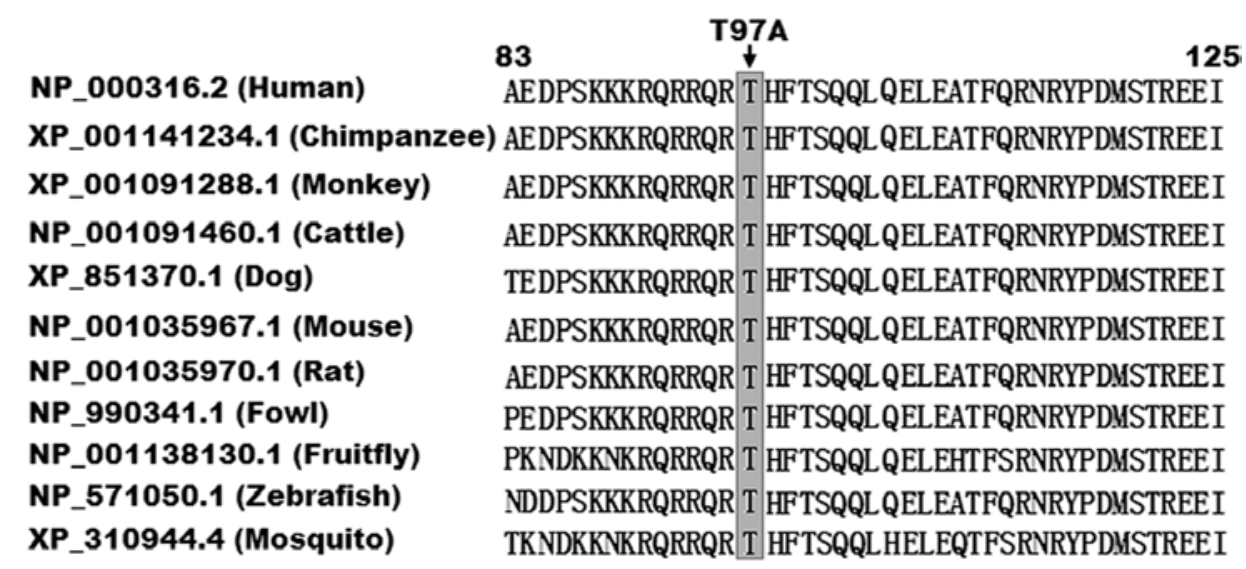

Figure 4. Alignment of multiple pituitary homeobox $2 \mathrm{c}$ protein sequences across species. The altered amino acid of p.T97 is completely conserved evolutionarily among various species.

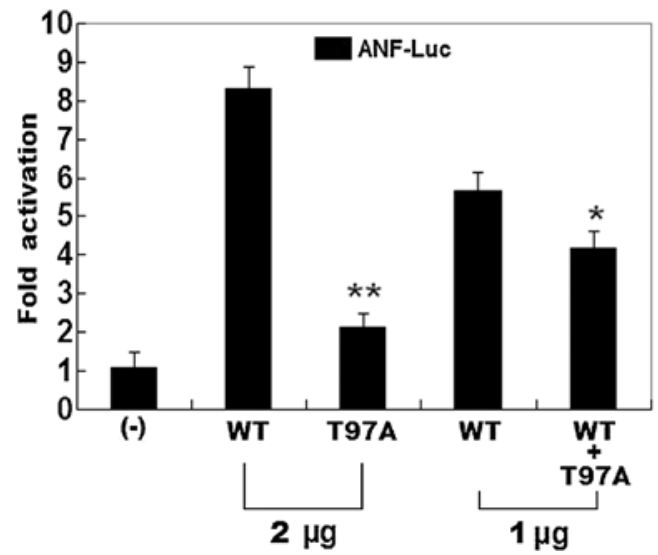

Figure 5. Functional defects associated with pituitary homeobox 2c (PITX2c) mutation. Activation of atrial natriuretic factor (ANF) promoter driven luciferase reporter in Chinese hamster ovary (CHO) cells by PITX2c wild-type (WT) or T97A-mutant, alone or in combination, demonstrated significantly decreased transactivational activity by mutant proteins. Experiments were performed in triplicate, and the mean and standard deviations are shown. ${ }^{* *} \mathrm{P}<0.001 ;{ }^{*} \mathrm{P}<0.005$, when compared with the same amount $(2 \mu \mathrm{g})$ of wild-type PITX2c

The unique amino-termini of PITX2a, PITX2b and PITX2c modify their ability to activate transcription in a cell type- and promoter-dependent manner. The homeodomain is responsible for recognizing specific DNA sequences (5'-TAATCC-3'), which is essential for DNA binding, nuclear translocation and interaction with other transcription factors (57). The human PITX2c gene maps to chromosome $4 \mathrm{q} 25$, which consists of three exons coding for a protein of 324 amino acids (58). PITX2c is expressed asymmetrically in the developing and adult heart, playing a crucial role in normal cardiovascular genesis and maturation (53). The PITX2c mutation of p.T97A identified in the present study is located in the homeodomain; thus, it can be hypothesized that it may affect the transcriptional activity of PITX2c by interfering with its DNA-binding ability.

Previous studies have validated that PITX2c is an upstream regulator of multiple target genes expressed in the heart during embryogenesis, including the gene that encodes ANF (59). Therefore, the functional effect of a PITX2c mutation can be explored by assay of the transcriptional activity of the $A N F$ promoter in cells expressing PITX2c mutant in contrast to its wild-type counterpart. In the present study, the functional characteristics of the novel PITX2c mutation identified in a patient with AF were investigated by transcriptional activity analysis and the results revealed that the mutation was associated with a significantly diminished transcriptional activity on a downstream gene, suggesting that dysfunctional PITX2c caused by mutation is potentially an alternative pathological mechanism of AF.

The association of functionally impaired PITX2c with the enhanced susceptibility to AF may be partially attributable to the abnormal development of the cardiovascular system, particularly the pulmonary venous myocardium (60). The pulmonary venous vessel is sheathed by a layer of myocardium known as the pulmonary myocardial sleeve, which has been implicated in the initiation and maintenance of $\mathrm{AF}$ by several presumably electrophysiological mechanisms, including increased automaticity, anisotropic arrangement of the myocardial fibers and delayed conduction that facilitate re-entry (61). It has been verified that PITX2c is abundantly expressed in the atria and pulmonary myocardium and functions as a repressor of the pacemaker lineage gene program by downregulating the sinoatrial nodal gene program, such as short stature homeobox 2 (ShOX2), hyperpolarization activated cyclic nucleotide-gated potassium channel 4 (HCN4) and Cav3.1, and upregulating a gene program characteristic of a working myocardium phenotype, i.e. NKX2-5, Cx40, Cx43, ANP and Kir2.1 $(48,51,53,60)$. In PITX2c knockout mice, a microarray analysis of gene expression profiles revealed that the sinoatrial nodal genes, ShOX2 and HCN4, were upregulated in the atrium, as well as a number of ion channel genes, including KCNQ1 (51). Therefore, PITX2c loss-of-function mutation may contribute to the switch of the atrial and pulmonary myocardium to a sinoatrial node-like phenotype, creating an arrhythmogenic substrate prone to AF.

It has been corroberated that there are some downstream genes transactivated by PITX2c (48) and loss-of-function mutations in several target molecules have been causally involved in AF, including NKX2-5, Cx40, Cx43 and ANF $(28,29-32,42,62)$. Therefore, mutated PITX2c may 
predispose to AF by downregulating the expression of such target genes.

In conclusion, to our knowledge, this is the first study on the association of PITX2c loss-of-function mutation with lone AF, which provides novel insight into the molecular mechanisms underlying AF, indicating potential implications for the early prophylaxis and allele-specific treatment of this prevalent type of arrhythmia.

\section{Acknowledgements}

The authors are really grateful to the participants for their dedication to the study. The present study was supported by grants from the National Natural Science Foundation of China (81070086, 81070153, 81270161 and 60103223) and the Natural Science Foundation of Shandong Province of China (ZR2010HM134 and Y2010C36).

\section{References}

1. Fuster V, Rydén LE, Cannom DS, Crijns HJ, Curtis AB, Ellenbogen KA, Halperin JL, Kay GN, Le Huezey JY, Lowe JE, Olsson SB, Prystowsky EN, Tamargo JL, Wann LS, Smith SC Jr, Priori SG, Estes NA III, Ezekowitz MD, Jackman WM, January CT, Lowe JE, Page RL, Slotwiner DJ, Stevenson WG, Tracy CM, Jacobs AK, Anderson JL, Albert N, Buller CE, Creager MA, Ettinger SM, Guyton RA, Halperin JL, Hochman JS, Kushner FG, Ohman EM, Stevenson WG, Tarkington LG and Yancy CW; American College of Cardiology Foundation/ American Heart Association Task Force: 2011 ACCF/AHA/HRS focused updates incorporated into the ACC/AHA/ESC 2006 guidelines for the management of patients with atrial fibrillation: a report of the American College of Cardiology Foundation/ American Heart Association Task Force on practice guidelines. Circulation 123: e269-e367, 2011.

2. Lloyd-Jones DM, Wang TJ, Leip EP, Larson MG, Levy D, Vasan RS, D'Agostino RB, Massaro JM, Beiser A, Wolf PA and Benjamin EJ: Lifetime risk for development of atrial fibrillation: the Framingham Heart Study. Circulation 110: 1042-1046, 2004

3. Miyasaka Y, Barnes ME, Gersh BJ, Cha SS, Bailey KR, Abhayaratna WP, Seward JB and Tsang TS: Secular trends in incidence of atrial fibrillation in Olmsted County, Minnesota, 1980 to 2000, and implications on the projections for future prevalence. Circulation 114: 119-125, 2006.

4. Benjamin EJ, Wolf PA, D'Agostino RB, Silbershatz H, Kannel WB and Levy D: Impact of atrial fibrillation on the risk of death: the Framingham Heart Study. Circulation 98: 946-952, 1998.

5. Wolf PA, Abbott RD and Kannel WB: Atrial fibrillation as an independent risk factor for stroke: the Framingham Study. Stroke 22: 983-988, 1991.

6. Wolowacz SE, Samuel M, Brennan VK, Jasso-Mosqueda JG and Van Gelder IC: The cost of illness of atrial fibrillation: a systematic review of the recent literature. Europace 13: $1375-1385,2011$

7. Darbar D, Herron KJ, Ballew JD, Jahangir A, Gersh BJ, Shen WK, Hammill SC, Packer DL and Olson TM: Familial atrial fibrillation is a genetically heterogeneous disorder. J Am Coll Cardiol 41: 2185-2192, 2003.

8. Ellinor PT, Yoerger DM, Ruskin JN and MacRae CA: Familial aggregation in lone atrial fibrillation. Hum Genet 118: 179-184, 2005.

9. Arnar DO, Thorvaldsson S, Manolio TA, Thorgeirsson G, Kristjansson K, Hakonarson H and Stefansson K: Familial aggregation of atrial fibrillation in Iceland. Eur Heart J 27: 708-712, 2006

10. Junttila MJ, Raatikainen MJ, Perkiömäki JS, Hong K, Brugada R and Huikuri HV: Familial clustering of lone atrial fibrillation in patients with saddleback-type ST-segment elevation in right precordial leads. Eur Heart J 28: 463-468, 2007.

11. Christophersen IE, Ravn LS, Budtz-Joergensen E, Skytthe A, Haunsoe S, Svendsen JH and Christensen K: Familial aggregation of atrial fibrillation: a study in Danish twins. Circ Arrhythm Electrophysiol 2: 378-383, 2009.
12. Yang YQ, Zhang XL, Wang XH, Tan HW, Shi HF, Fang WY and Liu X: Familial aggregation of lone atrial fibrillation in the Chinese population. Intern Med 49: 2385-2391, 2010.

13. Lubitz SA, Yin X, Fontes JD, Magnani JW, Rienstra M, Pai M, Villalon ML, Vasan RS, Pencina MJ, Levy D, Larson MG, Ellinor PT and Benjamin EJ: Association between familial atrial fibrillation and risk of new-onset atrial fibrillation. JAMA 304: 2263-2269, 2010

14. Fox CS, Parise H, D'Agostino RB Sr, Lloyd-Jones DM, Vasan RS, Wang TJ, Levy D, Wolf PA and Benjamin EJ: Parental atrial fibrillation as a risk factor for atrial fibrillation in offspring. JAMA 291: 2851-2855, 2004.

15. Brugada R, Tapscott T, Czernuszewicz GZ, Marian AJ, Iglesias A, Mont L, Brugada J, Girona J, Domingo A, Bachinski LL and Roberts R: Identification of a genetic locus for familial atrial fibrillation. N Engl J Med 336: 905-911, 1997.

16. Ellinor PT, Shin JT, Moore RK, Yoerger DM and MacRae CA: Locus for atrial fibrillation maps to chromosome 6q14-16. Circulation 107: 2880-2883, 2003.

17. Chen YH, Xu SJ, Bendahhou S, Wang XL, Wang Y, Xu WY, Jin HW, Sun H, Su XY, Zhuang QN, Yang YQ, Li YB, Liu Y, Xu HJ, Li XF, Ma N, Mou CP, Chen Z, Barhanin J and Huang W: KCNQ1 gain-of-function mutation in familial atrial fibrillation. Science 299: 251-254, 2003.

18. Oberti C, Wang L, Li L, Dong J, Rao S, Du W and Wang Q: Genome-wide linkage scan identifies a novel genetic locus on chromosome $5 \mathrm{p} 13$ for neonatal atrial fibrillation associated with sudden death and variable cardiomyopathy. Circulation 110: 3753-3759, 2004

19. Zhang X, Chen S, Yoo S, Chakrabarti S, Zhang T, Ke T, Oberti C, Yong SL, Fang F, Li L, de la Fuente R, Wang L, Chen Q and Wang QK: Mutation in nuclear pore component NUP155 leads to atrial fibrillation and early sudden cardiac death. Cell 135: 1017-1027, 2008.

20. Volders PG, Zhu Q, Timmermans C, Eurlings PM, Su X, Arens YH, Li L, Jongbloed RJ, Xia M, Rodriguez LM and Chen YH: Mapping a novel locus for familial atrial fibrillation on chromosome 10p11-q21. Heart Rhythm 4: 469-475, 2007.

21. Darbar D, Hardy A, Haines JL and Roden DM: Prolonged signal-averaged $\mathrm{P}$-wave duration as an intermediate phenotype for familial atrial fibrillation. J Am Coll Cardiol 51: 1083-1089, 2008.

22. Yang Y, Xia M, Jin Q, Bendahhou S, Shi J, Chen Y, Liang B, Lin J, Liu Y, Liu B, Zhou Q, Zhang D, Wang R, Ma N, Su X, Niu K, Pei Y, Xu W, Chen Z, Wan H, Cui J, Barhanin J and Chen Y: Identification of a KCNE2 gain-of-function mutation in patients with familial atrial fibrillation. Am J Hum Genet 75: 899-905, 2004

23. Hong K, Bjerregaard P, Gussak I and Brugada R: Short QT syndrome and atrial fibrillation caused by mutation in $\mathrm{KCNH} 2 . \mathrm{J}$ Cardiovasc Electrophysiol 16: 394-396, 2005.

24. Xia M, Jin Q, Bendahhou S, He Y, Larroque MM, Chen Y, Zhou Q, Yang Y, Liu Y, Liu B, Zhu Q, Zhou Y, Lin J, Liang B, Li L, Dong X, Pan Z, Wang R, Wan H, Qiu W, Xu W, Eurlings P, Barhanin J and Chen Y: A Kir2.1 gain-of-function mutation underlies familial atrial fibrillation. Biochem Biophys Res Commun 332: 1012-1019, 2005.

25. Olson TM, Alekseev AE, Liu XK, Park S, Zingman LV, Bienengraeber M, Sattiraju S, Ballew JD, Jahangir A and Terzic A: Kv1.5 channelopathy due to KCNA5 loss-of-function mutation causes human atrial fibrillation. Hum Mol Genet 15: 2185-2191, 2006.

26. Olson TM, Michels VV, Ballew JD, Reyna SP, Karst ML, Herron KJ, Horton SC, Rodeheffer RJ and Anderson JL: Sodium channel mutations and susceptibility to heart failure and atrial fibrillation. JAMA 293: 447-454, 2005.

27. Li RG, Wang Q, Xu YJ, Zhang M, Qu XK, Liu X, Fang WY and Yang YQ: Mutations of SCN $4 B$-encoded sodium channel $\beta 4$ subunit in familial atrial fibrillation. Int J Mol Med 32: 144-150, 2013.

28. Hodgson-Zingman DM, Karst ML, Zingman LV, Heublein DM, Darbar D, Herron KJ, Ballew JD, de Andrade M, Burnett JC Jr and Olson TM: Atrial natriuretic peptide frameshift mutation in familial atrial fibrillation. N Engl J Med 359: 158-165, 2008.

29. Gollob MH, Jones DL, Krahn AD, Danis L, Gong XQ, Shao Q, Liu X, Veinot JP, Tang AS, Stewart AF, Tesson F, Klein GJ, Yee R, Skanes AC, Guiraudon GM, Ebihara L and Bai D: Somatic mutations in the connexin 40 gene (GJA5) in atrial fibrillation. $\mathrm{N}$ Engl J Med 354: 2677-2688, 2006. 
30. Yang YQ, Zhang XL, Wang XH, Tan HW, Shi HF, Jiang WF, Fang WY and Liu X: Connexin40 nonsense mutation in familial atrial fibrillation. Int J Mol Med 26: 605-610, 2010.

31. Sun Y, Yang YQ, Gong XQ, Wang XH, Li RG, Tan HW, Liu X, Fang WY and Bai D: Novel germline GJA5/connexin40 mutations associated with lone atrial fibrillation impair gap junctional intercellular communication. Hum Mutat 34: 603-609, 2013.

32. Shi HF, Yang JF, Wang Q, Li RG, Xu YJ, Qu XK, Fang WY, Liu X and Yang YQ: Prevalence and spectrum of GJA5 mutations associated with lone atrial fibrillation. Mol Med Rep 7: 767-774, 2013.

33. Yang YQ, Wang MY, Zhang XL, Tan HW, Shi HF, Jiang WF, Wang XH, Fang WY and Liu X: GATA4 loss-of-function mutations in familial atrial fibrillation. Clin Chim Acta 412: 1825-1830, 2011.

34. Jiang JQ, Shen FF, Fang WY, Liu X and Yang YQ: Novel GATA4 mutations in lone atrial fibrillation. Int J Mol Med 28: 1025-1032, 2011.

35. Wang J, Sun YM and Yang YQ: utation spectrum of the GATA4 gene in patients with idiopathic atrial fibrillation. Mol Biol Rep 39: 8127-8135, 2012.

36. Yang YQ, Wang J, Wang XH, Wang Q, Tan HW, Zhang M, Shen FF, Jiang JQ, Fang WY and Liu X: Mutational spectrum of the GATA5 gene associated with familial atrial fibrillation. Int J Cardiol 157: 305-307, 2012.

37. Wang XH, Huang CX, Wang Q, Li RG, Xu YJ, Liu X, Fang WY and Yang YQ: A novel GATA5 loss-of-function mutation underlies lone atrial fibrillation. Int J Mol Med 31: 43-50, 2013.

38. Gu JY, Xu JH, Yu H and Yang YQ: Novel GATA5 loss-of-function mutations underlie familial atrial fibrillation. Clinics (Sao Paulo) 67: 1393-1399, 2012

39. Yang YQ, Wang XH, Tan HW, Jiang WF, Fang WY and Liu X: Prevalence and spectrum of GATA6 mutations associated with familial atrial fibrillation. Int J Cardiol 155: 494-496, 2012

40. Yang YQ, Li L, Wang J, Zhang XL, Li RG, Xu YJ, Tan HW, Wang XH, Jiang JQ,Fang WY and Liu X: GATA6 loss-of-function mutation in atrial fibrillation. Eur J Med Genet 55: 520-526, 2012.

41. Li J, Liu WD, Yang ZL and Yang YQ: Novel GATA6 loss-of-function mutation responsible for familial atrial fibrillation. Int J Mol Med 30: 783-790, 2012.

42. Huang RT, Xue S, Xu YJ, Zhou M and Yang YQ: A novel NKX2.5 loss-of-function mutation responsible for familial atrial fibrillation. Int J Mol Med 31: 1119-1126, 2013.

43. Gudbjartsson DF, Arnar DO, Helgadottir A, Gretarsdottir S, Holm H, Sigurdsson A, Jonasdottir A, Baker A, Thorleifsson G, Kristjansson K, Palsson A, Blondal T, Sulem P, Backman VM, Hardarson GA, Palsdottir E, Helgason A, Sigurjonsdottir R, Sverrisson JT, Kostulas K, Ng MC, Baum L, So WY, Wong KS, Chan JC, Furie KL, Greenberg SM, Sale M, Kelly P, MacRae CA, Smith EE, Rosand J, Hillert J, Ma RC, Ellinor PT, Thorgeirsson G, Gulcher JR, Kong A, Thorsteinsdottir U and Stefansson K: Variants conferring risk of atrial fibrillation on chromosome 4q25. Nature 448: 353-357, 2007.

44. Kääb S, Darbar D, van Noord C, Dupuis J, Pfeufer A, Newton-Cheh C, Schnabel R, Makino S, Sinner MF, Kannankeril PJ, Beckmann BM, Choudry S, Donahue BS, Heeringa J, Perz S, Lunetta KL, Larson MG, Levy D, MacRae CA, Ruskin JN, Wacker A, Schömig A, Wichmann HE, Steinbeck G, Meitinger T, Uitterlinden AG, Witteman JC, Roden DM, Benjamin EJ and Ellinor PT: Large scale replication and meta-analysis of variants on chromosome 4q25 associated with atrial fibrillation. Eur Heart J 30: 813-819, 2009.

45. Body SC, Collard CD, Shernan SK, Fox AA, Liu KY, Ritchie MD, Perry TE, Muehlschlegel JD, Aranki S, Donahue BS, Pretorius M, Estrada JC, Ellinor PT, Newton-Cheh C, Seidman CE, Seidman JG, Herman DS, Lichtner P, Meitinger T, Pfeufer A, Kääb S, Brown NJ, Roden DM and Darbar D: Variation in the $4 \mathrm{q} 25$ chromosomal locus predicts atrial fibrillation after coronary artery bypass graft surgery. Circ Cardiovasc Genet 2 . 499-506, 2009.
46. Husser D, Adams V, Piorkowski C, Hindricks G and Bollmann A Chromosome $4 \mathrm{q} 25$ variants and atrial fibrillation recurrence after catheter ablation. J Am Coll Cardiol 55: 747-753, 2010.

47. Ritchie MD, Rowan S, Kucera G, Stubblefield T, Blair M, Carter S, Roden DM and Darbar D: Chromosome 4q25 variants are genetic modifiers of rare ion channel mutations associated with familial atrial fibrillation. J Am Coll Cardiol 60: 1173-1181, 2012.

48. Clauss S and Kääb S: Is Pitx2 growing up? Circ Cardiovasc Genet 4: 105-107, 2011.

49. Haïssaguerre M, Jaïs P, Shah DC, Takahashi A, Hocini M, Quiniou G, Garrigue S, Le Mouroux A, Le Métayer P and Clémenty J: Spontaneous initiation of atrial fibrillation by ectopic beats originating in the pulmonary veins. N Engl J Med 339: 659-666, 1998

50. Douglas YL, Jongbloed MR, Deruiter MC and Gittenberger-de Groot AC: Normal and abnormal development of pulmonary veins: state of the art and correlation with clinical entities. Int J Cardiol 147: 13-24, 2011.

51. Wang J, Klysik E, Sood S, Johnson RL, Wehrens XH and Martin JF: Pitx 2 prevents susceptibility to atrial arrhythmias by inhibiting left-sided pacemaker specification. Proc Natl Acad Sci USA 107: 9753-9758, 2010.

52. Chinchilla A, Daimi H, Lozano-Velasco E, Dominguez JN, Caballero R, Delpón E, Tamargo J, Cinca J, Hove-Madsen L, Aranega AE and Franco D: PITX2 insufficiency leads to atrial electrical and structural remodeling linked to arrhythmogenesis. Circ Cardiovasc Genet 4: 269-279, 2011.

53. Kirchhof P, Kahr PC, Kaese S, Piccini I, Vokshi I, Scheld HH, Rotering H, Fortmueller L, Laakmann S, Verheule S, Schotten U, Fabritz L and Brown NA: PITX2c is expressed in the adult left atrium, and reducing Pitx $2 c$ expression promotes atrial fibrillation inducibility and complex changes in gene expression. Circ Cardiovasc Genet 4: 123-133, 2011

54. Strungaru MH, Footz T, Liu Y, Berry FB, Belleau P, Semina EV, Raymond V and Walter MA: PITX2 is involved in stress response in cultured human trabecular meshwork cells through regulation of SLC13A3. Invest Ophthalmol Vis Sci 52: 7625-7633, 2011.

55. Footz T, Idrees F, Acharya M, Kozlowski K and Walter MA: Analysis of mutations of the PITX2 transcription factor found in patients with Axenfeld-Rieger syndrome. Invest Ophthalmol Vis Sci 50: 2599-2606, 2009.

56. Acharya M, Lingenfelter DJ, Huang L, Gage PJ and Walter MA: Human PRKC apoptosis WT1 regulator is a novel PITX2-interacting protein that regulates PITX2 transcriptional activity in ocular cells. J Biol Chem 284: 34829-34838, 2009.

57. Simard A, Di Giorgio L, Amen M, Westwood A, Amendt BA and Ryan AK: The Pitx 2c N-terminal domain is a critical interaction domain required for asymmetric morphogenesis. Dev Dyn 238: 2459-2470, 2009.

58. Semina EV, Reiter R, Leysens NJ, Alward WL, Small KW, Datson NA, Siegel-Bartelt J, Bierke-Nelson D, Bitoun P, Zabel BU, Carey JC and Murray JC: Cloning and characterization of a novel bicoid-related homeobox transcription factor gene, RIEG, involved in Rieger syndrome. Nat Genet 14: 392-399, 1996.

59. Ganga M, Espinoza HM, Cox CJ, Morton L, Hjalt TA, Lee Y and Amendt BA: PITX2 isoform-specific regulation of atrial natriuretic factor expression: synergism and repression with $\mathrm{Nkx} 2.5$. J Biol Chem 278: 22437-22445, 2003.

60. Mommersteeg MT, Brown NA, Prall OW, de Gier-de Vries C, Harvey RP, Moorman AF and Christoffels VM: Pitx 2c and $\mathrm{Nkx} 2-5$ are required for the formation and identity of the pulmonary myocardium. Circ Res 101: 902-909, 2007.

61. Mommersteeg MT, Christoffels VM, Anderson RH and Moorman AF: Atrial fibrillation: a developmental point of view. Heart Rhythm 6: 1818-1824, 2009.

62. Thibodeau IL, Xu J, Li Q, Liu G, Lam K, Veinot JP, Birnie DH, Jones DL, Krahn AD, Lemery R, Nicholson BJ and Gollob MH: Paradigm of genetic mosaicism and lone atrial fibrillation: physiological characterization of a connexin 43-deletion mutant identified from atrial tissue. Circulation 122: 236-244, 2010. 